\title{
Knowledge, attitude and practice of preoperative visit: A survey of Nigerian perioperative nurses
}

\author{
Danjuma Aliyu ${ }^{1}$, , Ibrahim Taiwo Adeleke ${ }^{2,3,4}$, Sunday Oluwafemi Omoniyi ${ }^{5}$, Silas Kolo ${ }^{1}$, \\ Oluwafemi Michael Odofin ${ }^{6}$, Patience EssienEkaete ${ }^{1}$ \\ ${ }^{1}$ Department of Nursing Services, Ahmadu Bello University Teaching Hospital, Zaria, Nigeria \\ ${ }^{2}$ Department of Health Information, Federal Medical Centre, Bida, Nigeria \\ ${ }^{3}$ Centre for Health \& Allied Researches, Bida, Nigeria \\ ${ }^{4}$ Health Informatics Research Initiatives in Nigeria, Bida, Nigeria \\ ${ }^{5}$ Department of Nursing Services, Federal Medical Centre, Bida, Nigeria \\ ${ }^{6}$ Department of Nursing Services, Federal Teaching Hospital, Ido-Ekiti, Ekiti, Nigeria
}

\section{Email address:}

aliyudanjuma19@yahoo.com (D. Aliyu), ibratadeleke_aliseyin@yahoo.com (I. T. Adeleke), omonisunday@yahoo.com (S. O. Omoniyi), silcon12@yahoo.com (S. Kolo),olumic2005@yahoo.com (O. O. Michael), patoskie4u@yahoo.com (P. E. Essien)

\section{To cite this article:}

Danjuma Aliyu, Ibrahim Taiwo Adeleke, Sunday Oluwafemi Omoniyi, Silas Kolo, Oluwafemi Michael Odofin, Patience Essien Ekaete. Knowledge, Attitude and Practice of Preoperative Visit: A Survey of Nigerian Perioperative Nurses. American Journal of Health Research. Special Issue: Health Information Technology in Developing Nations: Challenges and Prospects Health Information Technology. Vol. 3, No. 1-1, 2015, pp. 54-60. doi: 10.11648/j.ajhr.s.2015030101.18

\begin{abstract}
Background: The notion of preoperative visiting has been in existence since the 1960s and its value and worth in relation to healthcare delivery has been debated consistently since the term preoperative-visit is often confusing. However, little is known about knowledge, attitude and practice of preoperative visits among perioperative nurses in Nigeria. Objectives: The study sought to determine knowledge, attitude and practice of Nigerian perioperative nurses towards the practice of preoperative visits and to identify barriers militating against the practice. Design: This is a countrywide cross-sectional descriptive survey. Results: One hundred and forty six Nigerian perioperative nurses among the conferenceattendees gave consent to participate in this study. Half of the participants- 70(50\%) of the participants worked with tertiary health facilitiesand 71(52.2\%) were from the conference host region (Southwest, Nigeria).The majority (97.3\%) of the participants possess good knowledge of preoperative visit. Equally, 139 (96\%)of them acknowledged that the practice of preoperative visit is very important to perioperative nursing careas well as to the teeming patients.About two-third (63\%) of the participants reported that they practice preoperative patient visit while $53(37 \%)$ did not. Ninety two (72\%) of the participants stated that they often document their opinions during preoperative visits to patients. Major factors militating against the practice of preoperative visit include timing of the visits (89\%) and work overload (66\%). It is equally important to note that $27(18 \%)$ of the participantsidentified shortage of perioperative nurses as a barrier to preoperative visit. Years of experience, workplace, age and professional rank were associated withthe practice of preoperative visit. Conclusion: Most perioperative nurses in Nigeria have formally acquired knowledge of preoperative visit. However, there is a notable gap between their knowledge and attitude towards it. Therefore, they require periodic reminder through continuing professional development programs on their responsibilities towards the recipients/beneficiaries of the perioperative nursing care.
\end{abstract}

Keywords: Preoperative Visit, Perioperative Nurses, Perioperative Nurse Patient Review, Operating Room Nurses, Knowledge, Practice, Nigeria

\section{Introduction}

Preoperativevisit, preoperative nurse visit, perioperative nurse patient assessment and perioperative nurse patient review are usedinterchangeably. The evolution of theatre nursing (perioperative nursing) is practically the same with the growth of surgery, not only because they developed together but because they complement each other.Perioperative nurses were formally referred to as "operating room nurses" a term that historically referred to 
patient care provided in the intraoperative period and practice within the operating room itself. However, as the responsibilities of the operating room nurses expended to care in the preoperative and postoperative periods, the term "perioperative" was recognized as more appropriate [1-2]. A perioperative nurse is a nurse who specializes in perioperative practice and who provides nursing care to the surgical patients throughout the continuum of care [3]. Perioperative nurses provide patients care within the framework of the nursing process; they use the tools of patient assessment, care planning, intervention, and evaluation of patient outcomes to meet the needs of the patients who will undergosurgery or other invasive procedures [2]. They also attend to the healthcare of patients in the operating room, oversee the work organization within the operating theatre, and mediate between various hospital departments, the surgeons, and the management of the hospital [4].Preoperative nurse patient review is one of the roles of a perioperative nurse meeting the patient one on one to interact, assess, educate and form a rapport with the patient prior to surgery [5]. Idusogie [6] states that preoperative visit is a mandatory visit during the surgical care of the client.

The notion of preoperative visit has been in existence since the 1960s and its value and worth in relation to care delivery has been debated consistently since the term preoperative visitis often confusing [7-11]. Equally, Alfredsdottir \& Bjornsdottir [12] affirmed that the complex role of the care provided by the perioperative nurse practitioner can easily be misunderstood. Cox [13] and Donworth [14] establish that perioperative care of patients consists of three main parts; a preoperative visit related to a nursing assessment of the patient, care of the patient during surgery and post-operative nursing care and evaluation of the patient.The benefits of preoperative visit to patients and theatre nurses undertaking pre-operative visits as a way of providing pre-operative information and teaching patients have been researched and documented [15-17]. Studies have shown that visiting patients in the preoperative period helps in post-operative recovery of patients and allow the patient the opportunity to express concerns and fears about the impending procedure [18-21]. Other benefits include; to collect data, to lessen the anxieties that the patient has towards his operation, to improve patient care by knowing the patient and his problems before operation, to help the patient to understand the procedures and the equipment needed for his care, to involve perioperative nurse more with total patient care and to encourage her to keep up-to-date with new procedures and ideals and to re-enforce information that the patient has already been given by ward nurses and surgeons[22-23 and $6]$. In the same vein, the value of giving pre-operative information to patients has been widely debated in the literatures, with many authors claiming that psychological preparation for an operation help in reducing hospital induced anxiety. Equally, Sadati et al [24] states that in some hospitals preoperative visit is advocated, particularly for those patients admitted a day before the surgery. However, preoperative visit has met with resistance from staff due to limited staffing, timing of the visits and availability of the patient themselves [25-28 and 6].

Despite the universallyacknowledged importanceof preoperative nurse patient visit to the provision of perioperative nursing care to surgical patients, its implementation especially in developing countries is low. This is largely detailed to be associated with unawareness/ inadequate knowledge among perioperative nurses on the concept of preoperative visit to patients, shortage of perioperative nurses in many hospitals, lack of time, fear ofpassing wrong information to the patient, unwillingness by the surgeons and anaesthetists to allow the perioperative nurses to visit patients and fear of information overload to the patient [5, 29].

\subsection{Aims of the Study}

To determine knowledge, attitude and practice of Nigerian perioperative nurses towards the practice of preoperative patient visit and to identify barriers militating against the practice.

\section{Methods}

\subsection{Background to the Study Area}

The study was carried out at the $14^{\text {th }}$ Annual Scientific/ $5^{\text {th }}$ Delegates' Conference of National Association of Perioperative Nurses of Nigeria (NAPON) held at Yessy Events Centre, along Gbongan-Ibadan Road, Owode, Osogbo, Osun State between Monday 13th and Friday 17th October 2014. NAPON is a registered association for all registered perioperative nurses in Nigeria under the umbrella of National Association of Nigerian Nurses and Midwives (NANNM). NAPON annual scientific/seminar conference was first inaugurated in the year 2000. The conference has been an annual event tailored to congregate all perioperative nurses all over the federation to brainstorm on ways of improving the standards of perioperative nursing practice all over Nigeria and to increase patients' satisfaction through quality surgical nursing care [30]. Perioperative nursing education program is a Post Basic Nursing program designed to equip the basic general nurses with the complexity of knowledge, skills and attitude required to effectively care for recipients of perioperative nursing services. The program is built upon the foundation of sciences and humanities [12]. To coordinate effective and efficient clinical practices that is considered paramount to obtain the best outcome of perioperative patient care [31].

\subsection{Study Design}

This is a nationwide cross-sectional descriptive survey of perioperative nurses in Nigeria.

\subsection{Study Population}

All Nigerian perioperative nurseswho attended the conference were eligible. 


\subsection{Sampling Techniques}

A convenience sample, randomly selected from the conference attendees was recruited for the study. A total of 146 gave their consent for participation.

\subsection{Data Collection Tools}

Eighteen item semi-structured questionnaire on KAP of preoperative nurses visits was administered to all perioperative nurses who gave consent to participate.

\subsection{Inclusion and Exclusion Criteria}

Participation in this study was restricted to perioperative nurses working inboth government and non-government health facilities in Nigeria. Other categories of nurses who attended the conference were excluded from the study.

\subsection{Data analysis and management}

Data analysis was done using SPSS 16.0 for windows to analyze the data. Descriptive analysis was computed on dependent and independent variables using Mean and Standard Deviation while test for significance was determined using Chi-square $(\chi 2)$ and p-value set at $P=0.05$.

\subsection{Ethics}

Approval was obtained from the National President of National Association of Perioperative Nurses of Nigeria
(NAPON) and the local organizers of the conference. Individual participant's informed consent was obtainedbefore administration of the questionnaire.

\section{Results}

\subsection{Socio-Demographic Characteristics}

Seventy nine $(54.1 \%)$ of the participants were females and the majority $(65.8 \%)$ were fifty years old or below, with a mean age of $45 \pm 8$ years. All participants have dual nursing professional qualifications or more. Participants work experience showed that $39(26.9 \%)$ of them had spent between 6-10 years in practice as registered perioperative nurses. One hundred and eight $(80.6 \%)$ of the participants were principal nursing officers and above. Half $(50 \%)$ of the participants worked with tertiary health facilities and more thanhalf $(52.2 \%)$ were from the South-west zone where the conference was held.

\subsection{Participants' KAP of Preoperative Visit}

As shown on Table 1,142 (97.3\%) of the participants acquired their knowledge of preoperative visit right from school and 139(96\%) of the participants acknowledged that the practice of preoperative visit is very important to the practice of a perioperative nurse and his patient (s). However, $53(36 \%)$ admitted that they do not conduct preoperative visit at their place of work.

Table 1. Participants' awareness, attitude and practice preoperative visit

\begin{tabular}{|c|c|c|c|c|}
\hline & $\mathbf{N}$ & Yes $(\%)$ & $\operatorname{No}(\%)$ & Unsure $(\%)$ \\
\hline Were you taught on the preoperative patient visit in your training school & 146 & $142(97.3)$ & $2(1.4)$ & $2(1.4)$ \\
\hline $\begin{array}{l}\text { How important is the practice of preoperative visits to the perioperative } \\
\text { nurses and the patient }\end{array}$ & 146 & $139(95.2)$ & $6(4.1)$ & $1(.7)$ \\
\hline $\begin{array}{l}\text { Did you carry out preoperative patient visit during your clinical/practical } \\
\text { posting as perioperative nurse student }\end{array}$ & 145 & $122(84)$ & $22(15)$ & $1(.7)$ \\
\hline Do you carry out preoperative patient visit at your present place of work & 145 & $92(63)$ & $53(37)$ & $0(0)$ \\
\hline Do you document your opinion during preoperative visits & 127 & $92(72.4)$ & $32(25.2)$ & $3(2.4)$ \\
\hline
\end{tabular}

\subsection{Knowledge on Benefits of Preoperative Visit}

Table 2 below demonstrates participants' basic knowledge of the intrinsic benefits of preoperative visit. One hundred and forty one $(96.6 \%)$ of the participants indicated that preoperative visit will lessen patients' anxieties regarding the operation, 94 (64.4\%) advanced improved patient's care as a result of fore knowledge of his predicaments and $1(0.7 \%)$ acknowledged that it will reduceethico-legal issues surrounding surgeries.

Table 2. Participants' knowledge on the benefits of preoperative visit

\begin{tabular}{|c|c|c|}
\hline Benefits & Frequency & $\%$ \\
\hline To lessen the anxieties that the patient has towards his operation & 141 & 96.6 \\
\hline Aid recovery of post-operative patients & 94 & 64.4 \\
\hline It allow patients the opportunity to express concerns and fears about the impending surgery & 137 & 93.8 \\
\hline Allows perioperative nurses to learn about their patients & 137 & 93.8 \\
\hline Establish good rapport & 136 & 93.2 \\
\hline Develop a plan of care before the patient arrives in the department & 134 & 91.8 \\
\hline To collect data & 133 & 91.1 \\
\hline To improve patient care by knowing the patient and his problems before operation & 94 & 64.4 \\
\hline
\end{tabular}




\begin{tabular}{lll}
\hline Benefits & Frequency & $\%$ \\
\hline To enable the perioperative nurse to anticipate equipment that may be needed for patients care & 130 & 89.0 \\
To help the patient to understand the procedures and the equipment that will be used in his care & 130 & 89.0 \\
To involve perioperative nurse more with total patient care and to encourage her to keep up to date with new procedures and ideals & 129 & 88.4 \\
To re-enforce information that the patient has already been given by ward nurses and surgeons & 127 & 11 \\
It reduces the rate of surgery cancellations & 11 \\
To ascertain the level of patient preparedness to surgery & 1 \\
It reduces the rate of ethics and legal issues associated with surgeries & 1.5 \\
To encourage the use of surgical checklist & 0.7 \\
\hline
\end{tabular}

\subsection{Barriers to Preoperative Visit}

Lack of time or wrong timing was identified by 130(89\%) among the participants (see Table 3), 97 (66.4\%) spotted work overload and 2 (1.4) sated that language barrier contribute to impediments of preoperative visit.

Table 3.Barriers to practice of preoperative visit

\begin{tabular}{|c|c|c|}
\hline Barriers & $\mathbf{N}$ & $\%$ \\
\hline Timing of the visits/ lack of time & 130 & 89.0 \\
\hline Unawareness/ inadequate knowledge among perioperative nurses on the concept of preoperative visit to patients & 38 & 26.0 \\
\hline Fear of passing wrong information to the patient & 26 & 17.8 \\
\hline Reluctance by the surgeons and anaesthetists to allow the perioperative nurses to conduct standalone visit to surgical patients & 24 & 16.4 \\
\hline Fear of information overload to the patients & 22 & 15.1 \\
\hline Work overload & 97 & 66.4 \\
\hline shortage of perioperative nurses manpower & 27 & 18.5 \\
\hline Hospital policy & 15 & 10.3 \\
\hline Language barrier & 2 & 1.4 \\
\hline
\end{tabular}

\subsection{Ways to Improve on Preoperative Visit}

Figure 1 shows that $121(83 \%)$ of the participants suggested adherence to standards as a major measure to improve preoperative visit.

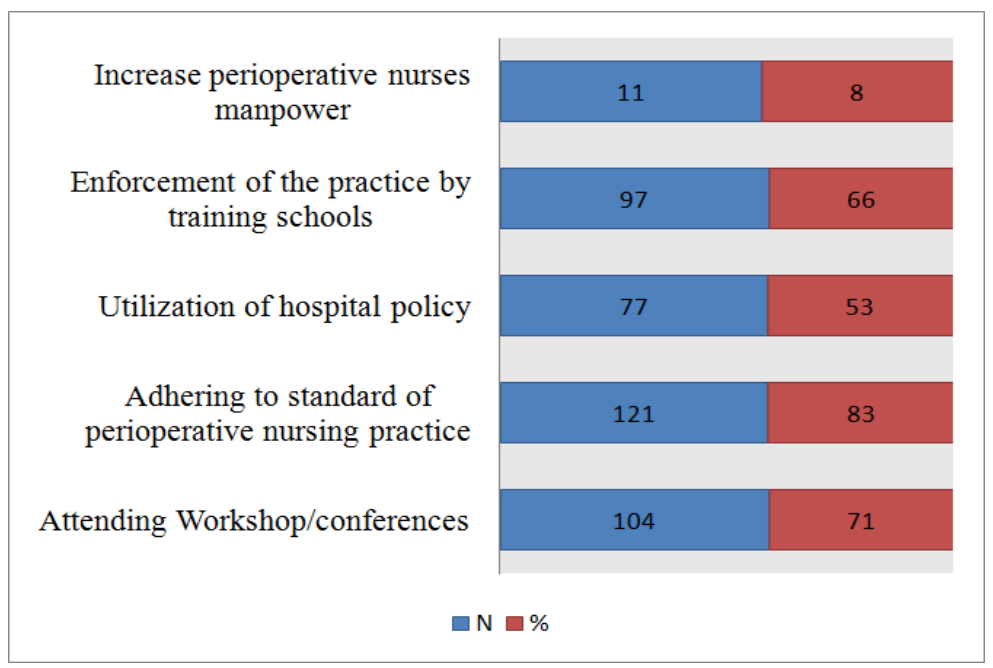

Fig. 1. Ways to improve preoperative visit practice

\subsection{Associations with KAP of Preoperative Visits}

Table 4 presents some significant factors associated with KAP of preoperative visit. Age and workplace were associated with practicing preoperative visit at training level. Other factors include rank and year of experience. 
Table 4. Factors associated with KAP of preoperative visit

\begin{tabular}{|c|c|c|c|c|c|c|c|c|}
\hline \multirow{2}{*}{ VARIABLES } & \multicolumn{2}{|l|}{$\mathbf{A}^{*}$} & \multicolumn{2}{|l|}{$\mathbf{Y}^{*}$} & \multicolumn{2}{|l|}{$\mathbf{R}^{*}$} & \multicolumn{2}{|l|}{ WP* } \\
\hline & $\chi^{2}$ & p-value & $\chi^{2}$ & p-value & $\chi^{2}$ & p-value & $\chi^{2}$ & $p$-value \\
\hline Were you taught preoperative visit in your training school & 2.648 & .989 & 41.698 & .000 & 9.548 & .976 & 28.963 & .011 \\
\hline ways to improve preoperative visit practice & 81.656 & .280 & 1.1088 & .513 & 1.524 & .431 & 1.214 & .131 \\
\hline $\begin{array}{l}\text { Did you carry out preoperative patient visit during your } \\
\text { clinical/practical posting as perioperative nurse student }\end{array}$ & 28.007 & .022 & 15.805 & .895 & 45.765 & .033 & 62.832 & .000 \\
\hline $\begin{array}{l}\text { Do you carry out preoperative patient visit at your present place } \\
\text { of work }\end{array}$ & 19.808 & .031 & 17.351 & .363 & 10.698 & .954 & 17.728 & .219 \\
\hline Documentation of opinions during preoperative visit & 17.596 & .285 & 21.898 & .585 & 18.908 & 942 & 10.428 & .973 \\
\hline Important of preoperative visit practice to nurses and the patients & 14.114 & 168 & 11.029 & .808 & 17.389 & .628 & 19.652 & 142 \\
\hline How often do you carry out preoperative visit to patients & 16.519 & .348 & 23.428 & .495 & 21.803 & .861 & 24.855 & .253 \\
\hline
\end{tabular}

\section{Discussion}

The demographic pattern of participants in this study shows that gender divide among the participants was somewhat pronounced as more than half $(54.1 \%)$ of the participants were female. This is in agreement with a study by Bamishaye \& Hinmikanye [32] which reported that 70\% of the operating room nurses were females. Contrary to our study Adeleke et al [33] reported that most participants in their study were male who possessed good behavior towards investigative healthcare. The preoperative assessment of patients enables the perioperative nurses to make need assessment and develop early stages of plan of care specific for the index patient. Conventionally, preoperative visit aims at reducing preoperative anxieties, aids recovery, to interact, assess, educate and form a rapport with the patient prior to surgery. It also allows the patient the opportunity to express concerns and fears about the impending procedure [16-18,5] The findings in our study concurs with these assertions asthe majority (96\%) of participants established that the practice of preoperative visits is very important to perioperative nursing and the patients. In a related development, $97 \%$ of the participants admitted that the practice of preoperative visit lessens the anxieties that patient has towards operations and $94 \%$ indicated that the practice allows patients the opportunity to express concerns and fears about the impending surgery. The same percentageagreed that it allows the perioperative nurses to learn about booked patients for surgeries in advance.

This study also found that Nigerian perioperative nurses (97.3\%) acquired knowledge of preoperative patient visits right from their respective training schools and are positively inclined to its importance to their practice and the patients. These finding agrees with a study on medical confidentiality [33] that most healthcare professionals affirmed to have good knowledge of confidentiality of patient's health records right from their respective training schools and are positively disposed to its relevance and importance to sound healthcare delivery. In a related development, years of experience $(p=.000)$ and workplace $(p=.011)$ had associationwith participants' knowledge of preoperative visits. Likewise, workplace $(p=.000)$ was found to have association with conduct of preoperative patient visit during clinical/practical posting of students perioperative nurses. However, it is equally demonstrated in our study that there is no association between stated actors and attitude of the participants towards preoperative visit.In spite of the documented facts [16-19] about the positive benefits of preoperative visitto patients, Williams [11] reported that the practice is still low in many units. Our findings are not in tandem with this report. For instance, $63 \%$ of the participants in our study established that they do conduct preoperative patients visit in their various places of work. Likewise, our study established that age $(p=.022)$, workplace $(p=.000)$ and professional rank $(p=0.033)$ were found to be associated with practice of preoperative patient visit. These findings go with a study [34] where workplace was a factor associated with perceptions of participants on health information technology. It is remarkable to state that $38 \%$ of the participants in this study do not occasionally conduct preoperative patient visits in their respective places of work especially at tertiary health facilitieswhich are presumed centres for research and training of most healthcare professionals in the country.

Reported barriers to perioperative visit practice shows that $89 \%$ of the participants identified wrongtiming of the preoperative visit or lack of time by the perioperative nurses to conduct the preoperative visit as a major contender to the practice. Another obvious barrier was work overload (66\%). Our discovery is relatively in agreement with a study [29] that the apparent difficulties with preoperative visit and subsequent assessment of patients were premised ontime and timing. On the contrary, other studies [ 35 and11] documented an incident where an anaesthetist positively discouraged and prevented preoperative nurses from practicing preoperative nurse patient visit for fear of information overload and saying the wrong thing to the patients.

\subsection{Study Limitations}

Most Nigerian perioperative nurses could not attend the conference due to the security challenges (Boko Haram Terrorism) in the country coupled with the outbreak of Ebola Virus Disease (EDV) as at the time of the study. As such, the findings in this study could not be generalized because $50 \%$ of the participants came from the conference host region of the country (South-western Nigeria). This might mean that their practice lacks divergence and varieties.

\section{Conclusion}

Most of the perioperative nurses in Nigeria have formally 
acquired knowledge of preoperative visit.There is a notable gap betweentheir knowledge and attitude toward preoperative visit. However, they require continuous reorientation through continuing professional education especially,with regards to their obligations towards recipients/beneficiaries of perioperative nursing services.

\section{Recommendations}

- There is a need for nationwide advocacy on the practice and implementation of preoperative patients visit at all the healthcare institutions.

- There is also a need to establish more perioperative nursing training schools in Nigeria to precludemanpower shortage in perioperative nursing practice in the country.

- In general, there is a need to organize Mandatory Continuous Professional Education Programs (MCPDP), training and retraining of perioperative nurses in Nigeria to get abreast with the new trends in perioperative nursing practice.

\section{Acknowledgement}

The authors wish to thank Messrs. A. A. Bello and A. A. Babatundeof the Department of Nursing Services OAUTHC Ile-Ife and Nurse S. Akpan of Federal Medical Centre, Bidafor theircomments and assistance in data collection. The thoughtful comments of the following nurses from Ahmadu Bello University Teaching Hospital, Zaria; Messrs. Y.Sani, S. A. Balarabe, C. C. Nmerengua, and Mrs. Dupe Oluyoriisgenuinely acknowledged.

\section{Competing Interest}

The authors declare that no competing interests exist.

\section{References}

[1] C. D. Hinmikaiye, E. I. Bamishaiye. The Incidence of Low Back Pain among TheatreNurses: A Case Study of University of Ilorin and ObafemiAwolowo University TeachingHospital International Journal of Nursing Science 2012;2(3):2328.doi:10.5923/j.nursing.20120203.02

[2] Association of Perioperative Registered Nurses (AORN) (2011). Perioperative NursingData Set (PNDS) Denver, CO: AORN. http://www.aorn.org. (Accessed 27 February2004) Association of periOperative registered Nurses. Restricted access for non-members American website useful for journal articles and references related to perioperative practice.

[3] Association of Perioperative Registered Nurses (AORN) (2012). Perioperative Standards and Recommended Practices. Denver, CO: AORN. Accessed September, 2012; http://www.aorn.org/WworkArea/DownloadAsset.aspx?id=21931.

[4] International Hazard Datasheets on Occupation: Nurse, Operating Room 1999, Publishedby the HDOEDIT (C) ILO/CIS.
[5] A. I. Emmanuel Perioperative nurse patient review: implications for outcome ofsurgery. ABUTH Nurses Magazine. 2014; No1 (1): 51-56.

[6] O. O. Idusogie. Questions and answers in Perioperative Nursing and Tit Bits. Mufti BooksNigeria, 33 Yoruba Road, Sapele, Delta State, Nigeria. 2007, pp 22, 32

[7] D.Kalideen. The case for preoperative visiting. British Journal of Theatre Nursing.1991;1(5): 19-21.

[8] P. Wicker.Preoperative visiting: making it work. British Journal of Theatre Nursing. 1995; 5(7): 16-19.

[9] D. Martin.Preoperative visits to reduce patient anxiety: a study of Nursing Standard. 1996; 10:23.

[10] B. Crawford. Highlighting the role of the perioperative nurseis preoperative assessmentnecessary? British Journal of Theatre Nursing.1999; 9 (7): 319-322.

[11] M. Williams. Preoperative visiting- an urban myth? British Journal of perioperativeNursing. 2002; 12(7): 168.

[12] H. Alfredsdottir, K. Bjornsdottir. Nursing and patient safety in theoperating room.Journal of Advanced Nursing. 2007; Vol. 61 (1) 29-37.

[13] H. Cox. The perioperative role (a personal view), NATNews. 1987; 24, No.1,15-16.

[14] G. Donworth. On the road to recovery, NATNews.1987;24, No.1, 12-14.

[15] A. Scott. Managing anxiety in ICU patients: the role of preoperative informationprovision. British Association of Critical Care Nurses, Nursing in Critical Care.2004; 9(2):72-79.

[16] S.Hayward. The Implementation of Pre-operative visiting. Natnews; 1989; 26: 13.

[17] K.Booth. Pre-operative visiting: a step-by-step guide - part 1 . British Journal of TheatreNursing. 1991;7: 30-31.

[18] J.Boore.Prescription for Recovery. London: Royal College of Nursing. 1978.

[19] G.Copp. Intra-operative information and pre-operative visiting Surgical Nurse.1988; 1:27-29.

[20] J. Hayward.Information: Prescription against Pain. London: Royal College of Nursing. 1975.

[21] L. A. Carol, S. I. Steven. Effect of Preoperative Visits By Operating Room Nurses.Nursing Research Journal. 1973; 22(1).

[22] Shaw, H. The Nursing Process, The Operating Theatre and Patient. Unpublished paper(1977); theatre nursing education and research fellowship fund.

[23] L. K. Groah, L. H. Nicolette. Perioperative Nursing. $\left(3^{\mathrm{d}}\right.$ Ed) Appleton and Lange Stamford, Connecticut.USA. 1996.

[24] L. Sadati, A. Pazouki, A. Mehdizadeh, et al. Effect of preoperative nursing visit onpreoperative anxiety and postoperative complications in candidates for laparoscopiccholecystectomy: a randomized clinical trial. Scand J Caring Sci; 2013; 27; 994-998.

[25] N. Phillips.Berry \& Kohn's Operating Room Technique.10th Ed. St. Louis: Mosby. 2004. 
[26] G. Amponsah, R. Insaful. Textbook for the Perioperative Nurse. University of GhanaMedical School Press. 2013; 1:4748.

[27] M. Taylor, C.Campbell. Surgical Practice. In: Clarke, P. \& Jones, J. (eds) Brigden's Operating Department Practice. Edinburgh: Churchill Livingstone. 1998.

[28] C.Torrance, E.Serginson.Surgical Nursing, $12^{\text {th }}$ edn. London: BaillièreTindall.1997.

[29] J. White, M. Coleman. Preoperative Visits in Wales. British Journal of Theatre Nursing. 1999; 9(10): 472-479.

[30] A. A.Babatunde. Keynote address paper presented at National Association of Perioperative Nurses of Nigeria (NAPON) $14^{\text {th }}$ Annual Scientific/ $/ 5^{\text {th }}$ Delegates' Conference held at Yessy Events Centre, Along Gbongan-Ibadan Road, Owode, Osogbo, Osun State, Nigeria.2014 (Unpublished paper).

[31] M. Schewchuk. Why a registered nurse (RN) in the OR? Canadian Operating RoomNursing Journal. 2007; 44(4):38-46.

[32] E. I. Bamishaiye,C. D. Hinmikaiye. The incidence of low back pain among theatrenurses: A case study of University of Ilorin and Obafemi Awolowo University Teaching Hospital. International Journal of Nursing Science. 2012; 2(3):23-28. doi:10.5923/j.nursing.20120203.02.

[33] I. T. Adeleke,A. O. Adekanye,S. A. Adefemi, et al. Knowledge, attitudes and practiceof confidentiality of patients Health Records among Health care professionals at FederalMedical Centre, Bida. Niger J Med. 2011; 20(2):228-235.

[34] I. T. Adeleke, S. A.Erinle, A. M. Ndana, T. C. Anamah, O. A. Ogundele, D. Aliyu. Health Information Technology in Nigeria: Stakeholders' Perspectives of Nationwide Implementations and Meaningful Use of the Emerging Technology in the Most Populous Black Nation. American Journal of Health Research. Special Issue: Health Information Technology in Developing Nations: Challenges and Prospects Health Information Technology.2014; 3(1-1):17-24. doi: 10.11648/j.ajhr.s.2015030101.13.

[35] M. Radford, B. County, M. Oakley. Advance Perioperative Practice Nelson Thomas Ltd Delta place 27 Bath Road Cheltenham G153 $7^{\text {th }}$ United Kingdom 2004; p.5,11-13, 31. 